\title{
A Scale to Assess Student Perceptions of Academic Climates*
}

\section{TERESA A. JANZ \& SANDRA W. PYKE}

York University

\section{ABSTRACT}

Sandler and Hall (1986) define a chilly academic climate as the “... subtle ways women are treated differently — ways that communicate to women that they are not quite first-class citizens in the academic community" (p. 1). This paper describes the construction of a scale to assess university students' perceptions of the chilly climate. An initial pool of 123 items was refined based on statistical analyses of the responses of 192 students to produce a 28 -item Perceived Chilly Climate Scale (PCCS). Factor analysis identified five factors: Climate Students Hear About; Sexist Treatment; Climate Students Experience Personally; Classroom Climate; and Safety. To investigate further the reliability and validity of the scale, the PCCS, an Alienation Scale (Dean, 1961) and the Marlowe-Crowne Social Desirability Scale (Reynolds, 1982) responses were gathered from 327 students. As expected, the PCCS was significantly related to alienation but unrelated to socially desirable responding. Additional evidence supporting the reliability and validity of the PCCS is presented.

* This article was prepared with financial assistance from an Ontario Graduate Scholarship and a Social Sciences and Humanities Research Council of Canada Doctoral Fellowship, 752-96-1553, to the first author. We wish to acknowledge the helpful suggestions of the three individuals who reviewed the manuscript. 


\section{RÉSUMÉ}

Pour Sandler et Hall (1986), le climat glacial qui règne dans les universités correspond à des moyens subtils de faire comprendre aux femmes qu'elles ne sont pas tout à fait des citoyennes de première classe dans le milieu universitaire. Cet article décrit la construction d'une échelle pour évaluer la perception des étudiants universitaires du climat glacial. Des analyses statistiques appliquées aux réponses fournies par 192 étudiants concernant un ensemble initial de 123 énoncés ont permis la création d'une échelle de Perception du Climat Glacial (Perceived Chilly Climate Scale; PCCS) composée de 28 énoncés. Une analyse factorielle a identifié cinq facteurs qui sont: le climat dont les étudiants entendent parler; le traitement sexiste; le climat que les étudiants éprouvent personnellement; le climat en classe; et la sécurité. Pour analyser la fidélité et la validité de l'échelle, nous avons demandé à 327 étudiants de compléter le PCCS, une échelle de régression (Dean, 1961) et le Marlowe-Crowne Social Desirability Scale (Reynolds, 1982). Comme prévu, les réponses obtenues au PCCS étaient très proches de celles obtenues à l'échelle de régression mais pas du tout des réponses se rapportant à l'échelle de désirabilité sociale. D'autres évidences qui corroborent la fidélité et la validité du PCCS sont présentées.

Many researchers have argued that there are characteristics of university settings which have a strong negative impact on the quality of education for women students (e.g., Cammaert, 1985; Caplan, 1993; Hall \& Sandler, 1982; 1983; 1984; Pyke, 1991; 1996; 1997; Sadker \& Sadker, 1986; Sandler \& Hall, 1986). Although the study of sexism in education is not a recent phenomenon, it was not until 1982 that researchers Bernice Hall and Roberta Sandler coined the term "chilly climate" to describe the "subtle ways women are treated differently ways that communicate to women that they are not quite first-class citizens in the academic community" (Sandler \& Hall, 1986, p. 1). Illustrative examples of sexist behaviours subsumed by this term include: the sexist use of language; sexual harassment; steering women away from participation in non-traditional fields; a higher frequency of contacting male students when professional opportunities arise; voicing 
stereotypical (disparaging) views of women; attributing female success to luck or a low level of task difficulty; and differential application of informal feedback, encouragement or praise for academic efforts. Chilly climate factors may come into play in any of a variety of areas including: mentoring and peer relationships, the curriculum, classroom interactions and during informal activities.

University faculty are predominately male, especially at senior levels. This shortage of women faculty limits the number of role models for women and the potential pool of mentors (Caplan, 1993), thereby contributing to a chilly climate. Male students are more likely to have access to the social networks important for professional advancement. The shortage of female faculty and of potential mentors also may be problematic because women faculty are often overburdened with committee responsibilities and thus are limited in terms of what they can do for female students (Caplan, 1993). The significance of having a same-sex mentor was dramatically illustrated in a study conducted by Goldstein (1979) who found that the subsequent academic productivity of those with same-sex supervisors exceeded the productivity of those who had opposite-sex supervisors. More recent work, however, has failed to replicate this result (Schuckman, 1987). Nevertheless, Braun (1990) reports that same-sex mentors are more important to women than to men. Moreover, Seagram, Gould and Pyke (1998) found that, relative to their male counterparts, women doctoral graduate students reported significantly less supervisor interest in their research topic and significantly fewer women than men collaborated with their supervisors on papers. Significantly more women than men believed that their gender had negatively affected their progress and women were significantly less satisfied with the supervisory experience overall than their male counterparts. The small number of women role models also reinforces the idea that women are marginalized - a point clearly articulated by a student in the Sandler and Hall (1986) study, who said:

I had a man advisor... There was only one woman who taught in the graduate school... The whole time I never did any work with any women professors ... and I began to think, "Where do I fit in the system if there are no women in it, or very few?" (p. 16) 
Women's under representation in the curriculum is another vehicle for the expression of a chilly climate (Minnich, 1990; Spender, 1982). Although in some specific disciplines or departments a concerted effort has been made to generate a more inclusive curriculum, it is generally the case that the curriculum content is androcentric (Wood, 1994). In psychology, for example, Kohlberg's theory of moral development was based entirely on male participants, and Piaget equates male development with the development of all children (Gilligan, 1993). Moreover, McClelland's theory of achievement was based totally on the experience of males. "In The Achievement Motive by McClelland, Atkinson, Clark, and Lowell (1953), only 8 of 400 pages described studies of women" (Templeman, 1994, p. 134). When these models are taught in psychology, they are typically presented as if they represent the experiences of all people (Torrey, 1987), and females are considered to contribute to "noise" or "error" when they deviate from the universal male norm (Katz, Boggiano, \& Silvern, 1993). As a result of this biased approach, women's experiences were and still are often distorted and misinterpreted (Westkott, 1979). Whether it is science, literature, history or politics, women's contributions are often minimized or totally ignored (Spender, 1982). These findings support the view of an androcentric bias in the education system and have obvious potential for generating a chilly climate for women students.

An important aspect of the hidden curriculum concerns the way that educators communicate with their female and male students and colleagues. Educators often possess differential expectations and hence respond differently to women and men. "From preschool through graduate education, teachers pay more attention to male students" (Wood, 1994 , p. 215). Women students and faculty are often praised for their appearance, personalities and nurturing qualities, while men are consistently praised for their academic interest and achievement (Hall \& Sandler, 1982, 1984; Sadker \& Sadker, 1986; Sandler \& Hall, 1986). The differential treatment of women and men also exists in advising relationships. Hall and Sandler (1984; Sandler \& Hall, 1986) have consistently found that more time, effort and encouragement are given to males as compared to female students. 
When considering the causes of such differential treatment, some researchers believe that instructors have differential expectations for male and female students and tend to treat them differently as a result (e.g., Hall \& Sandler, 1982; 1984; Janz \& Pyke, 1997; Sadker \& Sadker, 1994; Sandler \& Hall, 1986; Wood, 1994). Other researchers argue that differential treatment of students in the classroom occurs because of other variables, such as: class size (Constantinople, Cornelius, \& Gray, 1988; Crawford \& MacLeod, 1990), academic department, length of time in the course (Constantinople, Cornelius, \& Gray, 1988), sex of the instructor (Crawford \& MacLeod, 1990), a student's age or university experience (Crawford \& MacLeod, 1990), grades and confidence level (Crawford \& MacLeod, 1990; Strenta, Elliott, Adair, Matier \& Scott, 1994). Regardless of the etiology of differential treatment, the cumulative effects seem to have a negative impact on the self-esteem of female students (Wood, 1994).

Incidents of sexual harassment in universities provide a more direct illustration of the existence of the chilly climate. Estimates of the rates of sexual harassment vary considerably (Brooks \& Perot, 1991; Malovich \& Stake, 1990; McKinney, Olson \& Satterfield, 1988; Williams \& Cyr, 1992). Brooks and Perot, for example, reported that $63 \%$ of the women graduate students in their sample had been exposed to offensive jokes, seductive and/or sexist remarks, staring, leering, ogling and so on. In a review of this literature, Pyke (1996) found that the incidence of sexual harassment at Canadian universities ranged from $6 \%$ to $89 \%$ with an average of $36 \%$ of women faculty and students reporting the experience of some form of sexual harassment. While some individuals are sexually harassed by peers, research reveals that faculty are the perpetrators in most cases. A climate that encourages or does not discourage sexual harassment creates an environment of intimidation for female students (Wood, 1994). In such a context, women students receive a powerful message - that they are not valued for their intellectual contributions.

The consequences of being exposed to an environment that is not supportive, i.e., a chilly climate, are neither innocuous nor trivial. Such an environment can cause women to experience declining grades, loss of 
supervisor support, physical ailments and an array of psychological concomitants such as feelings of powerlessness, anger, frustration, dissatisfaction, shame, guilt and loss of self-esteem (Backhouse \& Cohen, 1982; Cammaert, 1985; Larkin, 1991; Seagram et al., 1998; Wood, 1994). Moreover, female students may even drop out or move to another school (Larkin, 1991). As a result of the myriad of consequences stemming from trying to function in a chilly academic climate, female students may also feel alienated or marginalized (c.f., Hall \& Sandler, 1982; 1983 ; 1984). Student alienation has been a focus of past research (e.g., Long, 1977; Middleton, 1972), and would appear to be theoretically related to the chilly climate construct. Just as researchers have found that racism is related to feelings of alienation (Middleton, 1972), we expect that sexism is similarly related.

At present, there are relatively few empirical studies that specifically examine the chilly climate, and there are no empirically validated tools to assess this construct. Even though there is evidence to support many facets of the chilly climate (e.g., sexual harassment), some researchers who have tried to assess these climate characteristics have concluded there is little or no evidence to support this phenomenon (Constantinople, Cornelius \& Gray, 1988; Crawford \& MacLeod, 1990; Heller, Puff \& Mills, 1985; Strenta, et al., 1994). Problems with the way researchers have assessed the chilly climate may have been what led to such conclusions. For example, Constantinople, Cornelius and Gray (1988) recognized that the main problem with their assessment of the chilly climate was that they focused simply on student-teacher behaviours (i.e., number and sex of students who spoke in class) which did not reflect the content of the interactions. Another limitation of their approach was the restricted number of chilly climate indicators that were investigated (only classroom behaviour). Assessments of the use of sexist language and humour, the devaluation of women's achievements, safety issues, curriculum content, advising and/or mentoring issues and sexual harassment were not included. A third problem with this approach was that many facets of the chilly climate deal with very sensitive issues (e.g., sexual harassment) that are extremely difficult to assess accurately using observational indices. 
Other researchers have assessed the chilly climate with short questionnaires asking students about their perceptions of the academic environment (Heller et al.,1985; Crawford \& MacLeod, 1990). The principal difficulty with these scales was their restricted focus or narrow operational definition of the chilly climate. For example, the Heller et al. (1985) scale focused primarily on classroom interactions and did not include questions regarding students' feelings of safety on campus, treatment by ones' peers, treatment by faculty outside the classroom and in advising relationships, and the curriculum. Moreover, when considering sexual harassment, Heller and colleagues only asked students about "direct sexual overtures" which most researchers suggest occur less frequently than more subtle harassing behaviours (Fitzgerald \& Ormerod, 1993; Pyke, 1996). Crawford and MacLeod (1990) assessed the chilly climate with an adaptation of the Student Perception Questionnaire created by Jenkins, Gappa and Pearce (1983), that focused on perceptions of student-teacher interactions. This scale was also problematic as a measure of chilly climate, because it explored only behaviours inside the classroom and did not examine perceptions of sexual harassment, safety, the curriculum or mentoring relationships. Thus both of these measures failed to include many important aspects of the chilly climate. Additionally, in neither study was there any indication of the reliability or validity of the scales. Therefore, there continues to be a need for a comprehensive, valid and reliable measure that can be used in future research and evaluation of academic environments.

Thus the rationale for Study 1 was to develop a chilly climate scale that improved upon previous studies assessing the chilly climate. We also wanted the scale to be psychometrically robust (i.e., reliable and valid). Third, we wanted to develop a measure that reflected Hall and Sandler's (1982; 1983; 1984; Sandler \& Hall, 1986) vision of the chilly climate - i.e., one which covered all of the aforementioned components of the chilly climate. In addition to using a theoretical approach, statistical methods such as factor analysis were also used in the development of this scale.

To test the reliability and validity of the scale, we considered several hypotheses regarding the relationship between the chilly climate scale 
and several student demographic variables in both Study 1 and Study 2 . In terms of sex differences, we expected women to be more likely than men to view the climate as hostile. This assumption is based on the fact that the chilly climate is a measure of sexism, or negative attitudes and behaviour directed at women. Although we predicted that women would perceive the climate as chillier than men, past research suggested that other variables might influence perceptions of the chilly climate. For example, if women have internalized the sexist stereotypes of our society (Unger \& Crawford, 1996) they may not be aware of, or may even deny personal discrimination (Crosby, Pufall, Snyder, O'Connell \& Whalen, 1989). Conversely, students who have been through a consciousness raising experience are more aware of systemic sexism. Thus we predicted that students specifically educated about sexism (i.e., by taking a women's studies or gender studies course) are presumably more conscious of it, and this would be reflected in their evaluation of the university. Similarly, since women who label themselves feminists are less likely to deny discrimination (Klonis, Endo, Crosby, \& Worell, 1997), we also hypothesized that they would be more aware of the chilly climate. Since both sexism and racism may be viewed as forms of oppression, we predicted that disadvantaged groups in general (i.e., minority-group students) would be more aware of the chilly climate relative to non-minority-group students. A sixth hypothesis we tested to examine the validity of the chilly climate scale was related to the length of time students had been in school. We anticipated that graduate students would be more sensitive than undergraduates to chilly climate issues since they would have attended university longer and would presumably be more knowledgeable of climate issues.

Finally, one method of examining the validity of a scale is to correlate it with other valid and reliable scales that assess constructs considered to be theoretically related. We decided to correlate the chilly climate scale with alienation in Study 2 for several reasons. First, several researchers have hypothesized and/or assessed the relationship between perceptions of the academic environment and alienation (e.g., Hall \& Sandler, 1982; Long, 1977; Middleton, 1972). Second, a valid and reliable scale exists to assess alienation - Dean's Alienation Scale 
(Robinson \& Shaver, 1973). In sum, the purpose of Study 1 was to develop a psychometrically robust scale to assess students' perceptions of the chilly academic climate. Further assessments of the reliability and validity of the scale were obtained in Study 2 .

\section{METHOD}

\section{Item Generation}

The deductive or theoretical approach was used to generate items for this scale. First, a clear definition of the chilly climate was written based on the literature, and items were generated to represent this definition. In order to improve on previous scales (e.g., Crawford \& MacLeod, 1990; Heller et al., 1985), we examined diverse aspects of the chilly climate including: mentoring, curriculum, informal activities, peer interactions, safety, sexist behaviour, and sexual harassment as well as experiences in the classroom. The reports authored by Hall and Sandler (1982; 1983; 1984; Sandler \& Hall, 1986) were particularly useful sources for the development of items. Ideas for items also came from research in progress (Pyke \& Maxwell, 1995; Seagram et al., 1998), and from scales that were designed to assess the chilly climate directly (e.g., Crawford \& MacLeod, 1990; Heller et al., 1985), or intended to assess a related construct such as sexual harassment (e.g., Fitzgerald, Drasgow \& Gelsand, 1993). Finally, additional questions were generated so there were equal numbers of items covering each component of the chilly climate. These initial procedures ensured that the scale had face validity.

To reduce the possibility of acquiescence or dissentience response sets, half of the items were positively-keyed and half were negativelykeyed (c.f., Helmes \& Reddon, 1993). The researchers also reviewed the items to ensure that they were clear, specific, nonrepetitive, unambiguous or leading, and devoid of double-negatives. This procedure resulted in the creation of a 123-item Preliminary Perceived Chilly Climate Scale (PPCCS). The response format selected was a seven-point Likert-type scale (1: "strongly disagree", to 7: "strongly agree"). The response alternatives, "do not know" and "does not apply" were also permitted for each item. 


\section{Respondents}

A questionnaire package was distributed to 697 graduate and undergraduate university students from a large Canadian university. A total of 202 questionnaires were returned. Ten of the questionnaires were rejected because participants failed to answer at least $80 \%$ of the items, leaving a total of 192 usable questionnaires. Thus the response rate was approximately $28 \%$. Although this response rate may appear to be relatively low, it is typical for mail surveys of this kind. For example, McDaniel and Van Roosmalen (1991) reported a response rate of $28 \%$ for their survey; Bradley, MacMillan and Chrisjohn (1992) reported a $30 \%$ response rate; while Fitzgerald and Ormerod (1991), and Fitzgerald, Weitzman, Gold and Ormerod (1988) indicated that their response rates were $32 \%$ and $29 \%$ respectively. Additionally, most respondents $(71 \%)$ indicated that this scale was too long, which probably militated against a higher response rate.

There were 153 female (80\%) and $39(20 \%)$ male participants in the final sample. Most of the participants were Canadian citizens $(\mathrm{N}=176$; $92 \%)$. Thirty percent $(\mathrm{N}=58)$ of the respondents reported that they belonged to some sort of minority group (e.g., ethnic, racial). Most of the students in the sample, which was comprised of $41 \%$ undergraduates and $58 \%$ graduate students (20\% and $38 \%$ at the Master's and Ph.D. levels respectively), attended university full time ( $\mathrm{N}=174 ; 91 \%)$. The majority of respondents were psychology majors (71\%), although $6 \%$ were in law, $6 \%$ in sociology, $5 \%$ in biology and $12 \%$ had other majors. The respondents' ages varied from 21 to 49 years with an average age of 28 . Seventy percent of the students were between 21 to 30 years old. Seventy-two percent of the students had been attending university from 1 to 10 years.

\section{Procedure}

The questionnaire package distributed to the students consisted of the PPCCS, a background questionnaire, a consent form, instructions for returning the questionnaire and a list of appropriate campus agencies to contact in the event that any of the participants had concerns regarding 
how the teaching staff had treated them or other students. The background questionnaire included demographic items as well as other questions designed especially for validating the chilly climate scale. The demographic questions asked the student's: sex, age, years in university, programme of study and major. We also asked if the student belonged to a minority group(s). One example of a question that was important for assessing the validity of the scale was "would you describe yourself as a feminist." The responses ranging from 1 ("no I am definitely not a feminist") to 3 were grouped as non-feminist responses, and the participants who circled 5, 6, or 7 (i.e., "yes, I am definitely a feminist") were categorized as feminist respondents. Another question of particular interest asked if the student had taken any courses that focused on gender or women's studies. All data were gathered anonymously in order to decrease the possibility of socially desirable responding.

This package was distributed to 416 graduate students and 281 undergraduate students. All participants were given a verbal or written description of the study and assured that their participation was completely voluntary. Students were solicited from a diverse group of undergraduate classes including: sociology, psychology, statistics, biology, geography, chemistry, law, administrative studies and environmental studies. Graduate students were drawn from graduate programs in psychology, biology, sociology, geography and social and political thought.

\section{RESULTS AND DISCUSSION}

\section{Criteria for Item Inclusion}

Several criteria were used to refine the PPCCS. First, frequency distributions of every item were examined. Items were deleted if more than $10 \%$ of the respondents failed to answer the question, or selected the response alternatives "do not know" or "does not apply." Such responses indicate that the item may not be appropriate because it is not applicable to most students' experiences, or the item may be too complex to answer. Ten items met this criterion and were removed.

Next, the variance of each item was considered by examining frequencies and histograms of every item. An item with a very small variance is 
problematic because it will not add to the scale's reliability and validity (Jackson, 1970). Preference was given to items with bimodal distributions indicative of items that discriminate between individuals who perceive the climate to be chilly versus those who do not. Furthermore, with respect to the frequency distribution, items were retained if at least $15 \%$ of the participants responded at the low and high ends of the distribution. Forty-four items met these criteria for deletion.

Next, each item was examined to investigate its contribution to the internal consistency of the scale. Three procedures were employed: item correlation, factor analysis and an examination of Cronbach's alpha. Items that correlated a minimum of $r=.3$ with the total score were retained. This criterion resulted in the deletion of five items.

At this stage, 64 items remained on the PPCCS. For the factor analysis, an oblimin factor rotation was selected because it was hypothesized that the factors of the PPCCS would be correlated since they were all selected to relate to the chilly climate. Several researchers have argued that factor analysis is essential in scale construction and should precede the process of empirical validation (e.g., Aiken, 1989; Anastasi, 1982; Briggs \& Cheek, 1986; Dawis, 1987). It helps to determine the existence of subscales when an item pool is believed to be multidimensional. This allows for the reduction of a large number of items to a smaller sample without a loss in information (Dawis, 1987).

According to Pedhazur and Schmelkin (1991), there is considerable debate regarding how large a sample should be when computing a factor analysis. Cliff (1987) has suggested 150 participants as the minimum for a factor analysis. With 192 respondents in Study 1, this study meets the minimum sample size requirements. The selection of the number of factors followed the application of the scree test (i.e., a plot of the total variance associated with each factor), and an examination to determine whether items within each factor had a similar underlying or shared meaning. This procedure resulted in the identification of five factors: (a) Climate Students Hear About; (b) Sexist Treatment; (c) Climate Students Experience Personally; (d) Classroom Climate; and (e) Safety. Investigation of the factor loadings was completed in order to eliminate additional items. Factor loadings of $| \pm .40|$ were 
selected as the minimum loading for including an item on the scale. Using these criteria, nine items were deleted.

The next step in the construction of this measure involved investigating each of the remaining 55 items with respect to its contribution to the internal consistency of the scale as assessed with Cronbach's alpha. If deleting an item increased Cronbach's alpha it was removed from the scale. The next items considered for deletion were ones that caused the least decline in alpha relative to the other items. Through this process, we adhered to our goal of developing a scale with a reliability greater than .70 . Twenty-seven items were deleted using Cronbach's alpha as a criterion.

The final version of the Perceived Chilly Climate Scale (PCCS) consisted of 28 items (see Table 1 for a summary of the remaining items and their factor loadings). The mean inter-item correlation was .31 , which is within the optimal range of .2 to .4 recommended by Briggs and Cheek (1986). The overall Cronbach's alpha was .92, which is considered to be high for this type of assessment instrument (Aiken, 1989). Fourteen items are worded such that positive responses indicate a chilly climate, and the remaining 14 items are worded such that positive responses suggest a benign climate. Thus the scale was balanced with respect to positive and negative-keyed items. The overall mean score on the 28 -item scale was 99 (with a possible lower limit of 28, an upper limit of 196, and a midpoint of 112). The higher the score on the scale, the chillier the student perceives the environment to be. The actual range of scores found for the participants in this study was from 39 to 178 .

\section{Validity Analyses}

As predicted, a significant sex difference was found on the PCCS scores, $t(190)=3.61, p<.0003$ (one-tail), with female respondents $(M=103 ; S D=33)$ perceiving the academic climate to be chillier than males $(M=82 ; S D=28)$. Additionally, a significant difference was obtained between students who defined themselves as feminists as compared to those who did not, $t(152)=4.28, p<.0003$ (one-tailed). The former group $(M=105 ; S D=35)$ perceived the climate to be 'colder' than students who did not describe themselves as feminists $(M=83 ; S D=20)$. 
Seventy-four percent of the women respondents identified themselves as feminists, $11 \%$ said they were not feminists, while $15 \%$ chose an intermediate response. With respect to men, $47 \%$ described themselves as feminists, $21 \%$ did not describe themselves as feminists and $32 \%$ opted for the neutral response. Thus although there is some overlap between being female and labelling oneself a feminist, identification with the feminist label, irrespective of gender, seems to have an impact on one's awareness of the chilly climate.

We also predicted that students who have taken courses focusing on women's studies or gender-issues would be more aware of the chilly climate because of exposure to a consideration of sexism. These assumptions were supported by the data. There was a significant difference in perception of the chilly climate between students who had taken a course that focussed on gender issues $(N=102 ; M=104 ; S D=34)$, as compared with students who had not taken such a course $(M=92$; $S D=31), t(189)=2.5, p<.008$ (one-tailed). Similarly, respondents who had taken a women's studies $(N=68)$ course perceived the climate to be significantly chillier $(M=106 ; S D=34)$ than students who had never taken a women's studies course $(M=95 ; S D=32), t(187)=2.3, p<.01$ (one-tailed). It is likely that more females than males have taken a women's studies course. This is certainly true in this sample where $41 \%$ of the women have taken a women's studies course as compared to only $16 \%$ of the men. Thus while gender may be a confound of this particular finding, it does not wholly explain the results.

Our next hypothesis concerned the comparison of minority and nonminority group students. Students who labelled themselves as belonging to a visible minority group, as defined and/or identified by the researchers, were included for comparison. Nineteen percent of the students met this criteria. Our data supported the hypothesis that minority-group students $(M=106 ; S D=35)$ perceived the climate as significantly "chillier" than non-minority group students $(M=97 ; S D=32), t(190)=1.5, p<.05$ (one-tail).

Finally, we expected that students who had been in school longer would be more aware of covert discrimination since prolonged exposure may increase awareness. To test this assumption, the chilly climate 
scores of Doctoral students were compared with undergraduate students. This difference was significant $(t(148)=1.5, p<.05$, one-tail) with the Doctoral students obtaining higher scores $(M=105 ; S D=31)$ than the undergraduate students $(M=96 ; S D=34)$. Since this hypothesis concerns the length of time students are in school, it is interesting to note that in this study, students in an undergraduate program had attended school for an average of three years $(S D=1.8)$, while the Doctoral students spent an average of nine years $(S D=2.1)$ in university.

In sum, the results of Study 1 indicate that the PCCS is a reliable, multifactor scale, consisting of five factors. Although preliminary indications with respect to the validity of the PCCS are also encouraging, it is important to assess further the reliability and validity of this scale.

\section{STUDY 2}

The main purpose of the second study was to carry out further investigations into the validity and reliability of the PCCS. There are seven main expectations associated with Study 2. Our first two hypotheses concerned the reliability of the PCCS. In accordance with Study 1, we expected Cronbach's alpha to be above .70. Additionally, we expected to replicate the factor loadings and factor structure found in Study 1.

When considering the validity of a scale that assesses sensitive issues, it is important to examine its relationship with socially desirable responding. A valid scale should not reflect social desirability. Since the scale in Study 1 was very long, we did not include a social desirability scale because we were concerned that the length would deter respondents from participating. Therefore, it was necessary to examine this relationship in Study 2. We expected to find no significant relationship between the PCCS and the Marlowe-Crowne Social Desirability Scale.

Examining the relationship between two theoretically related constructs can be done to further assess the construct validity of a scale. As previously mentioned, alienation is theoretically related to the chilly climate. Thus Dean's (1961) valid and reliable Alienation Scale (Robinson \& Shaver, 1973) was used in Study 2 to further examine the validity of the PCCS. We predicted that the more hostile the student perceives the 
university environment, the more alienated he/she will feel (i.e., a positive correlation between the PCCS and the Alienation Scale).

Finally, to further assess the validity of this scale we attempted to replicate the findings of Study 1. Again, we predicted that women, minority group students and graduate students would perceive the climate as less friendly when compared with men, non-minority group students and undergraduate students, respectively.

\section{METHOD}

\section{Respondents}

A questionnaire package was distributed to a sample of 488 undergraduate $(88 \%)$ and graduate students $(12 \%)$ at the same university. A total of 327 students returned completed questionnaires: 269 females $(80 \%), 57$ males $(17 \%)$, and nine respondents who did not indicate their sex. This difference in the response rate between females and males is typical of questionnaire research that has been recently completed at this institution (Kohn, O’Brien \& Pickering, 1996; Lay 1996). Three questionnaires were discarded because they were incomplete. The undergraduate students were enrolled in the following disciplines: Anthropology, Statistics, Psychology, Economics, Administrative Studies, or Philosophy. The students represented 14 different faculties with 38 different major areas of study. The ages of the respondents in this study ranged from 19 to 54 years with an average age of 25 years.

The improved response rate (67\%) as compared with that of Study 1 (28\%), may reflect the difference in the time commitment to respond to the questionnaires. The combined three scales in Study 2 (65 items in total) were appreciably shorter than the PPCCS (123 items). A second possible explanation for the improved response rate for Study 2 is that fewer questionnaires were mailed in Study 2 as compared to Study 1 . Typically, questionnaires sent by mail yield lower response rates than questionnaires distributed personally. Third, more students were allowed class time to complete the questionnaires in Study 2 as compared to Study 1, where all students were obliged to work on the questionnaires on their own time. 
Thirty-nine percent of the respondents indicated that they belonged to a minority group. On average, students had been attending university for 3 years, ranging from a few months to 15 years. A majority of the students were completing an undergraduate degree (90\%), while $10 \%$ were graduate students. The percent of graduate and undergraduate students in this sample is a close approximation of the population of students at this university (Levy, 1996).

\section{Procedure}

The procedure followed in Study 1 was essentially duplicated. Every participant completed a background questionnaire consisting of seven questions that provided demographic information. The 28-item PCCS developed in Study 1 was also given to the participants. In order to further assess construct validity for the PCCS, the Alienation Scale (Dean, 1961) and the short form of the Marlowe-Crowne Social Desirability Scale (Reynolds, 1982) were also included in the questionnaire package.

\section{RESULTS AND DISCUSSION}

The average score on the 28-item PCCS was $98(S D=27)$, with a range of 36 to 179 . An oblimin factor analysis was calculated in order to compare the results with those in Study 1. Again, five factors were identified which best represented the items. The factor loadings were very similar to those found in Study 1 (see Table 1).

\section{Item Analyses}

First, the score on each PCCS item was correlated with the total score. All items were significantly correlated with the total score $(p<.0005)$ and the lowest item-total correlation was .29 . The corrected mean inter-item correlations were examined next. This procedure involved correlating each item with the average score of the remaining items (Norusis, 1990). The mean inter-item correlation for the PCCS was .24 , which is within the range of .1 to .5 suggested by Briggs and Cheek (1986). 
Table 1

PCCS Items and Oblimin Factor Pattern Matrix Loadings

Items

$$
\begin{array}{cc}
\multicolumn{2}{c}{\text { Loadings }} \\
\text { Study } 1 & \text { Study } 2 \\
(N=192) & (N=327)
\end{array}
$$

\section{Factor 1: Climate Students Hear About}

*3. I have NEVER HEARD that a female student has been

sexually harassed by a member of the teaching staff.

5. I have HEARD of one or more instances where a member of the teaching staff put a female student down or was rude to her because she was female.

6. I have HEARD of one or more instances where a member of the teaching staff has used humour (e.g., sexual/sexist humour, or told sexually suggestive stories, jokes, etc.) to "liven up" the class.

*7. I have NEVER HEARD that a member of the teaching staff has attempted to establish a sexual relationship with a female student.

8. I have HEARD of one or more instances when a member of the teaching staff has engaged in inappropriate physical contact toward a female student.

17. I have HEARD of a member of the teaching staff treating female students as though they have limited intellectual ability.

18. I have HEARD that some members of the teaching staff have said things that made female students feel uncomfortable.

*26. I have NEVER HEARD that a member of the teaching staff has made crude and offensive sexual remarks to female students.

\section{Factor 2: Sexist Attitudes and Treatment}

2. The teaching staff most often use examples from men's lives.

*4. In general, I believe that the academic climate at this university is very supportive of female students. 
Table 1 (continued)

Items

\section{Loadings}

Study $1 \quad$ Study 2

$(N=192) \quad(N=327)$

9. A woman student must outperform male students in order to be taken seriously by the teaching staff.

10. Some teaching staff have "put down" or belittled specific individuals who raise feminist issues or take a feminist position in the classroom.

11. The teaching staff generally seem to associate particular occupations or achievements with one sex (e.g., by saying, "suppose you went to the doctor and he..."; or "suppose you spoke with a psychologist and she...".

12. Teaching staff have made sexist remarks (e.g., suggesting that women are too emotional to be scientists, or men are too aggressive to be caretakers of the young or elderly).

\section{Factor 3: Climate Students Experience Personally}

1. A member of the teaching staff has treated me as though I have limited intellectual ability.

*13. Most teaching staff have supported and encouraged me to obtain my academic goals (e.g., provided emotional support, important information, etc.)

16. I have received an unfair grade due to differences in opinion between myself and a member of the teaching staff.

23. I have made a comment in a class that has been ignored, and later another student received credit for my idea.

25. A member of the teaching staff has incorrectly seemed to think that I was incompetent when I asked a question.

*27. Most teaching staff seem to have enough time to meet with me. 
Table 1 (continued)

Items

Loadings

$$
\begin{array}{cc}
\text { Study } 1 & \text { Study } 2 \\
(N=192) & (N=327)
\end{array}
$$

\section{Factor 4: Classroom Climate / Course Material}

*14. Topics regarding women (e.g., women's contributions . $\quad .50$ to the field) are integrated into the course material in most of the classes I have taken.

*15. Most teaching staff have assigned readings that were .40 written by women.

*20. Course material is presented from a broad range of perspectives (i.e., includes many ways of looking at the same material, includes the perspective of women, etc.)

*21. Most of my textbooks contain some examples of feminist research.

*22. Most teaching staff seem to respond just as well to female students as they do to male students.

\section{Factor 5: Safety}

* 19. I have HEARD that most female students are NOT afraid to go to the library alone at night.

*24. I am not afraid to go to the library alone at night.

*28. The campus is a relatively safe place.

* These items are reverse scored, that is, $1=7 ; 2=6 ; 3=5 ; 4=4 ; 5=3 ; 6=2 ; 7=1$

\section{Reliability of the Scales}

When a scale contains a Likert-type response format, the reliability should be computed for every study because reliability is a function of both the scale and the respondent sample (Dawis, 1987). Thus, the internal consistency reliabilities were calculated for all of the scales used in Study 2 (Table 2). 
Table 2

\section{Reliability of the Scales}

Scales

Cronbach's Alpha

Marlow-Crowne Social Desirabilty Scale

Perceptions of Chilly Climate (Study 2)

.90

Alienation Scale

.84

The reliability for the PCCS was again very high $(\alpha=.90)$. Although the reliability for the Marlowe-Crowne Social Desirability Scale was relatively low $(\alpha=.65)$ it is nevertheless acceptable for the purposes of this study. Aiken (1989) argues that when test scores are used to compare whether groups of people differ, “...then a reliability coefficient as low as .65 may be satisfactory" (p. 78). Since the reliability of the Alienation Scale was quite high $(\alpha=.84)$, comparisons with this scale are also appropriate for this study.

\section{Testing Expectations}

No significant relationship was expected between PCCS and social desirability scores. As predicted, these scales were not significantly correlated, $r(327)=.001, p=.99$. In addition to examining the overall correlation, each item was examined to determine whether or not it correlated with the social desirability scale. None of the items were significantly correlated with the social desirability scale.

It was anticipated that the more hostile a respondent perceived the climate to be, the more alienated he/she would feel (i.e., a positive correlation). As predicted, students' perceptions of chilly climate were significantly related to feelings of alienation, $r(327)=.30(p<.0003)$. Correlating the PCCS subscales with alienation (Table 3 ) allowed for a closer look at this relationship. All of these correlations were significant $(p<.05)$. Alienation was most strongly correlated with Factor 2: Sexist Attitudes and Treatment $(r(327)=.32, p<.0003)$ and Factor 3: Climates Students Experience Personally $(r(327)=.32, p<.0003)$. 
Table 3

\section{Correlations Between PCCS Subscales and Alienation Scale} $N=327$

Subscale Pearson Correlation

Factor 1: Climate Students Hear About $.17^{* *}$

Factor 2: Sexist Attitudes and Treatment

Factor 3: Climate Students Experience Personally $.32 * *$

Factor 4: Classroom Climate / Course Material $.30^{* *}$

Factor 5: Safety

** Correlation is significant at the 0.01 level (one-tailed)

* Correlation is significant at the 0.01 level (one-tailed)

Relatively weaker correlations were evident between alienation and the remaining subscales.

Third, when considering the validity of the PCCS, we predicted that students who indicated that they belonged to a minority group would experience the climate to be less friendly when compared with nonminority group students. A t-test was used to examine this relationship. As expected, minority group students $(M=102 ; S D=27)$ perceived the climate as significantly more chilly than non-minority group students $(M=95 ; S D=26), t(316)=2.0, p<.02$ (one-tail).

Similar to Study 1 , it was predicted that females would score higher on the PCCS, indicating that they perceived the climate to be more hostile as compared with their male counterparts. As predicted, women $(M=101 ; S D=27)$ perceived the climate as significantly "chillier" than men $(M=84 ; S D=21), t(324)=4.4, p<.0003$ (one-tail).

Again, similar to Study 1 , the relationship between the length of time in school and perceptions of the chilly climate was assessed. A t-test was used to compare graduate students with undergraduate students' scores on the PCCS. As predicted, graduate students $(M=122$; $S D=34)$ perceived the university as more hostile than undergraduate students $(M=96 ; S D=25), t(325)=4.32, p<.0003$ (one-tail). 
Undergraduate students had attended school for an average of 3 years $(S D=1.6)$, while graduate students had been in university for an average of 7 years $(S D=2.6)$. Taken together, the findings of Study 1 and Study 2 indicate that there is a relationship between the length of time students attend school and their perception of the chilly climate. Students who are in school longer perceive the climate more negatively.

\section{GENERAL DISCUSSION AND SUMMARY}

The results of these two studies indicate that the PCCS is both a valid and a reliable scale. With respect to reliability, in each study, the PCCS was found to be highly reliable as assessed by Cronbach's alpha ( $\alpha=.92$ and $\alpha=.90$ in Study 1 and 2 respectively). Moreover, the fact that the factor loadings for the items were replicated in Study 2 provides additional evidence for the scale's reliability.

There are several findings that indicate the PCCS is a valid measure of the perception of a chilly climate. First, we predicted that certain groups of students (i.e., women, graduate, and minority group students) would be more sensitive to issues of sexism than other students (i.e., males, undergraduate, and non-minority group students). These predictions were supported in both Studies 1 and 2. The relationship between the PCCS and feminism provides additional evidence for the validity of the measure, as does the relationship between scores on the PCCS and participation in women studies or gender courses. Further evidence of the construct validity of the instrument was provided by the fact that significant correlations were found between the chilly climate and feelings of alienation. Moreover, the PCCS did not correlate with socially desirable responding. More evidence of the validity of the scale was provided by the fact that the five factors on the PCCS were easy to interpret in both studies because the items comprising each factor were all theoretically related and reflected the predictions derived from the chilly climate literature. Thus the PCCS fills an identifiable need for a reliable and valid measure of the extent to which individuals perceive academic environments to be inhospitable and unwelcoming. Another benefit of this scale is that because of the way the questions were designed, it is applicable for 
both undergraduate and graduate students. Additionally, this scale provides the most complete description of the chilly climate of any scales that have previously been developed. Given the potentially debilitating consequences of exposure to such environments on both a personal and systemic level, it is critical that an appropriate instrument be available to study this phenomenon.

It is important to emphasize that this scale is a measure of one's perceptions of the climate as opposed to being an "objective" assessment tool, and perceptions may differ from "reality." While it is necessary to assess both perceptions and objective indicators of the chilly climate, there were several reasons why we chose to examine student perceptions at this time. First, it is not always possible to accurately assess chilly climate factors objectively. For example, sexual harassment is often underreported (Fitzgerald \& Ormerod, 1993) and it may be possible to obtain more accurate estimates of the problem from anonymous questionnaires as opposed to examining archival records of the number of formal complaints. Furthermore, the best way to determine students' perceptions of the supportiveness of the environment is to ask them directly.

Another reason why it is important to assess perceptions of the climate is because not every individual will perceive the climate in the same way. It is possible for chilly climate indicators to exist, but some individuals may consider the situation to be "normal" (Sandler \& Hall, 1986) or attribute such treatment to personal failings rather than discrimination (Crosby et al., 1989). In order for individuals to perceive the climate as chilly, they must recognize that chilly behaviours are not "normal" and are, in fact, a type of discrimination. That is why it is not surprising that some students do not recognize negative treatment. Obviously, an individual's perception differs from reality because personal biases, assumptions and learning may all have influenced what is perceived. Thus it would be interesting for future investigations to examine the extent to which students' perceptions relate to "objective" measures.

What can we say about these students' perceptions of the chilly climate? One might argue that, on average, there are not strong perceptions of "chilliness." That is, the average scores on the PCCS were lower than the midpoint of the scale (i.e., 112) for both Study $1(M=99)$ and Study 2 
$(M=98)$. On the other hand, this also means that $33 \%$ of the students in Study 1, and $26 \%$ in Study 2 scored above the midpoint, perceiving the climate as chilly. So while some may argue that if only one-third of the students identify the overall climate as chilly, then it is not a problem. Others might argue that if the goal is equality for all students then these data suggest that some improvements are necessary at this institution.

Students are a very heterogeneous group but the organizational structure, curriculum and teaching methods are very homogeneous (Ferguson, 1992; Pascarella \& Terenzini, 1991). All students, regardless of their individual characteristics (e.g., sex and race), should have equal opportunity to experience both the academic and social benefits of attending a post-secondary institution. When the climate is perceived as more hostile by some groups of students, equality has not been achieved. Sexism is a social problem that researchers should fully investigate to increase awareness and encourage the development of prevention programmes and social policy changes. Universities that support research on such issues will be better able to respond to student needs. Moreover, individual women should not be expected to change the systemic problem of sexism in academe. Rather, university policy should address discrimination. Since policy decisions can well be influenced by personal perceptions, this chilly climate scale may be useful in guiding change. Hopes and goals for what the institution should be like can also inspire policy changes. For example, policy and programmes could be developed to address the recruitment and promotion of women faculty, the elimination of sexist attitudes and behaviour in the classroom, the inclusion of women in the curriculum, the importance of educating the entire university community about climate issues, the provision of support for faculty and students who are primary care-givers, pay equity, and the evaluation of the university climate (c.f., Caplan, 1993; Pascarella \& Terenzini, 1991; Sandler \& Hall, 1986).

There are some limitations to this research that should be noted. First, the generalizability of these findings is uncertain. The sample was neither random nor representative of all Canadian universities. In fact, students from only one university were included in these two studies. Although non-random samples are quite common in psychology studies 
(Carlson, 1971) and studies of the chilly climate (e.g., Heller et al., 1985), nevertheless, this must also be considered a limitation in this study. One way the sample may have biased the findings is that the students in Study 1 were older, on average, than students in the population. Relatively more graduate students were sampled during scale development to obtain diverse responses to the items, which is important when considering the scale's reliability and validity (Jackson, 1970). Moreover, students who have been in university for a longer period of time are likely to be more familiar with educational settings and, therefore, may be able to make more accurate judgements about the academic environment. Additionally, we felt it was important to include graduate students during scale development because they generally have a closer working relationship with faculty and would be better able to comment on the chilly climate aspects of supervision than undergraduate students. Thus the inclusion of graduate students did not likely bias the data in an unreasonable way.

In addition to the presence of more senior students, it is also important to note that more female students responded to this questionnaire than males, relative to their representation in the population. For example, in Study 2, $80 \%$ of the sample were females versus $60 \%$ in the population, and $17 \%$ of the sample were males versus $40 \%$ in the population (Levy, 1996). As previously explained, these disproportionate response rates between male and female students are typical of volunteer research at this university. However, other explanations for the low response rate of male students in this particular study may apply. Several males responded that questions concerning sexism were not important or relevant to them. Additionally, some male students may have felt that the questionnaire was unfairly biased in favour of women. For example, one male student wrote that, "there appears to be an abundance of time and effort spent making mountains out of molehills." While the chilly climate may not be an issue that is important to some male students, it can be argued that the "molehills" this student is speaking about may have a cumulative negative effect on women, and it may be the case that some women view the hostility of the climate as representing a "mountain" (c.f., Caplan, 1993, for a similar analogy). 
The relatively low response rate for Study $1(28 \%)$ may have also had an impact on the findings if the respondents differed from nonrespondents. Perhaps the students who responded were more interested in this topic as compared with those who decided not to respond. However, as mentioned previously, the low response rate seems to reflect a difficulty in Study 1 with the length of the scale. In Study 2, the scale was considerably shorter and the response rate was notably better $(67 \%)$.

A final limitation to consider is that the current scale focuses on different forms of sexist treatment and systemic discrimination that may occur in an academic environment. It does not encompass all possible discriminatory experiences (i.e., racism, heterosexism, ageism, ableism, and classism). Different forms of discrimination may conjointly produce a hostile environment and we hope this scale will be amenable to modification for assessment of other types of discrimination. Additionally, it is hoped that in the future this scale will be easily adapted to assess faculty experiences and those in other communities, such as business settings.

An examination of how the PCCS subscales were related to feelings of alienation provides some ideas for future research. Alienation was most strongly correlated with Factor 2: Sexist Attitudes and Treatment, and Factor 3: Climate Students Experience Personally. Relatively weaker correlations were found between alienation and Factor 1: Climate Students Hear About, Factor 4: Classroom Climate/Course Material, and Factor 5: Safety. Intuitively, it makes sense that students would find it more alienating if they personally experienced the climate as chilly versus hearing about their peers' experiences of sexist treatment. It would be interesting to study the types of attributions made by students who, for example, hear about sexist treatment but feel they are exempt from it. The fact that some of the PCCS subscales were not as strongly correlated with alienation as the others, raises another issue. Perhaps some aspects of the chilly climate have more negative consequences. This finding also indicates the importance of focussing on the different facets of this phenomenon (e.g., classroom interactions, mentoring, sexist language, sexism that students hear about, curriculum, sexual harassment and concerns about safety) and the impact that each one has on students. 
Future studies could also investigate the relationship between the chilly climate scale and other potential consequences. For example, past research has examined the relationship between the chilly climate and students' self-confidence, self-esteem, perceptions of themselves and their education (e.g., Heller et al., 1985), aspirations for their future education and career (e.g., Strenta et al., 1994) and any of the consequences outlined in the Project on the Status and Education of Women papers (i.e., Ehrhart \& Sandler, 1987; Hall \& Sandler, 1982; 1983; 1984; Sandler \& Hall, 1986). Although researchers have investigated several potential consequences of the chilly climate, studies have yet to explore the impact on students' academic performance, satisfaction and their physical and emotional health.

Another possible consequence of the chilly climate is that students may feel like intellectual impostors, or what Clance and Imes (1978) have called the Impostor Phenomenon. Although Clance and Imes indicate that the Impostor Phenomenon may partly originate as a result of one's family history, they also note that societal stereotypes suggesting that women are intellectually the "weaker sex" may intensify impostor feelings. There is some evidence that universities are not free of such societal stereotypes, and may therefore perpetuate the impostor phenomenon in women. In fact, researchers (Baranowsky \& Collins, 1995; King \& Cooley, 1995) have found that significantly more female university students, as compared to males, feel like "impostors." Moreover, impostor scores were negatively correlated with feeling capable in school and positively correlated with feeling held back. Thus future validity tests for the chilly climate scale could examine the relationship between the Impostor Phenomenon and students' experiences with a chilly environment.

Although we have listed several possible detrimental consequences of the chilly climate, obviously not all students suffer when faced with a toxic environment. Thus it would also be interesting to know how students cope and what helps buffer them from experiencing negative consequences. For example, if students identify the discrimination they face as a systemic problem rather than a consequence of individual failings, are they better able to cope? 
Perceptions of the climate are not only a result of individual differences, but we also expect the climate to vary across different classrooms, departments and institutions. Thus the possibility exists for instructors to use the scale to assess their own classroom. Moreover, researchers could investigate differences between departments within a university (e.g., compare women's studies classes with those in the sciences), and between universities to identify the socio-political factors related to hostile environments. Whether this scale is sensitive to such climate differences remains to be determined. Another means of testing the sensitivity of the scale to climate variations is in an experimental design. For example, if students used the scale to rate a videotaped chilly classroom and also a classroom devoid of examples of sexism, would the scale discriminate between the two "simulated" classrooms. If researchers could identify the types of classrooms, departments, and university environments that students perceive as warm, these would provide helpful models for improvement.

In recent studies of the chilly climate, researchers have operationally defined this construct very narrowly (e.g., classroom interactions). Our primary concern with these previous studies was that a once very broadly defined construct (i.e., the chilly climate) was becoming truncated. Our goal with the development of this scale was to improve upon previous scales and expand the definition to reflect more faithfully the original vision of the chilly climate researchers (i.e., Ehrhart \& Sandler, 1987; Hall \& Sandler, 1982; 1983; 1984; Sandler \& Hall, 1986). Hopefully, research on this construct will contribute to the creation of environments that foster the development of all students.

\section{References}

Aiken, L.R. (1989). Assessment of personality. Boston, MA: Allyn and Bacon. Anastasi, A. (1982). Psychological testing (5th ed.). New York, NY: Macmillan Publishing Co., Inc..

Backhouse, D., \& Cohen, L. (1982). Sexual harassment on the job. Englewood Cliffs, NJ: Prentice-Hall. 
Baranowsky, A.B., \& Collins, C. (1995, June). Am I what I am? Impostor feelings in young men and women. Poster presented at the 56th annual meeting of the Canadian Psychological Association, Charlottetown, PEI.

Bradley, M.D., MacMillan, A., \& Chrisjohn, R. (1993, May). Sexual harassment and the female graduate student. Paper presented at the meeting of the Canadian Psychology Association, Montreal, PQ.

Braun, R. (1990). The downside of mentoring. In L. B. Welch (Ed.), Women in higher education: Changes and challenges (pp. 191-198). New York, NY: Praeger.

Briggs, S.R., \& Cheek, J.M. (1986). The role of factor analysis in the development and evaluation of personality scales. Journal of Personality, 54, 106-148.

Brooks, L., \& Perot, H. (1991). Reporting sexual harassment: Exploring a predictive model. Psychology of Women Quarterly, 15(1), 31-42.

Carlson, R. (1971). Where is the person in personality research? Psychological Bulletin, 75(3), 203-219.

Cammaert, L.P. (1985). How widespread is sexual harassment on campus? Special issue: Women in groups and aggression against women. International Journal of Women Studies, 8(4), 388-397.

Caplan, P.J. (1993). Lifting a ton of feathers: $A$ woman's guide to surviving in the academic world. Toronto, ON: University of Toronto Press.

Clance, P.R., \& Imes, S.A. (1978). The impostor phenomenon in high achieving women: Dynamics and therapeutic intervention. Psychotherapy: Theory, Research and Practice, 15(3), 241-247.

Cliff, N. (1987). Analyzing multivariate data. San Diego, CA: Harcourt Brace Jovanovich.

Constantinople, A., Cornelius, R., \& Gray, J. (1988). The chilly climate: Fact or artifact? Journal of Higher Education, 59, 527-550.

Crawford, M., \& MacLeod, M. (1990). Gender in the college classroom: An assessment of the "chilly climate" for women. Sex Roles, 23(3/4), 101-122.

Crosby, F.J., Pufall, A., Snyder, R.C., O'Connell, M., \& Whalen, P. (1989). The denial of personal disadvantage among you, me and all the other ostriches. In M. Crawford \& M. Gentry (Eds.), Gender and thought: Psychological perspectives (pp. 79-99). New York, NY: Springer-Verlag.

Dawis, R.V., (1987). Scale construction. Special issue: Quantitative foundations of counselling psychology research. Journal of Counselling Psychology, 34(4), 481-489. 
Dean, D.G. (1961). Alienation: Its meaning and measurement. American Sociological Review, 26(5), 753-758.

Ehrhart, J.K., \& Sandler, B.R. (1987). Looking for more than a few good women in traditionally male fields. Washington, DC: Project on the Status and Education of Women, Association of American Colleges.

Ferguson, M. (1992). Is the classroom still a chilly climate for women? College Student Journal, 26(4), 507-511.

Fitzgerald, L.F., Drasgow, F, Gelsand, M. (1993). Sexual experience questionnaire: Form E. Unpublished research scale, Department of Psychology, University of Illinois at Urbana-Champaign.

Fitzgerald, L.E., \& Ormerod, A.J. (1991). Perceptions of sexual harassment: The influence of gender and academic context. Psychology of Women Quarterly, 15(2), 281-294.

Fitzgerald, L.E., \& Ormerod, A.J. (1993). Breaking the silence: The sexual harassment of women in academia and the workplace. In F.L. Denmark, \& M.A. Paludi (Eds.), Psychology of women: A handbook of issues and theories (pp. 553-581). Westport, Conneticut: Greenwood Press.

Fitzgerald, L.F., Weitzman, L.M., Gold, Y., \& Ormerod, M. (1988). Academic harassment: Sex and denial in scholarly garb. Psychology of Women Quarterly, 12, 329-340.

Gilligan, C. (1993). In a different voice: Psychological theory and women's development. Cambridge, MA: Harvard University Press.

Goldstein, E. (1979). Effect of same sex and cross-sex role models on the subsequent academic productivity of scholars. American Psychologist, 34(5), 407-410.

Hall, R.M. \& Sandler, B.R. (1982). The classroom climate: A chilly one for women? Washington, DC: Project on the Status and Education of Women, Association of American Colleges.

Hall, R.M. \& Sandler, B.R. (1983). Academic mentoring for women students and faculty: A new look at an old way to get ahead. Washington, DC: Project on the Status and Education of Women, Association of American Colleges.

Hall, R.M. \& Sandler, B.R. (1984). Out of the classroom: A chilly campus climate for women? Washington, DC: Project on the Status and Education of Women, Association of American Colleges.

Heller, J.F., Puff, C.R. \& Mills, C.J. (1985). Assessment of the chilly college climate for women. Journal of Higher Education, 56(4), 446-461.

Helmes, E. \& Reddon, J.R. (1993). A perspective on developments in assessing psychopathology: A critical review of the MMPI and MMPI-2. Psychological Bulletin, 113(3), 453-471. 
Hornick, C.W., James, L.R., \& Jones, A.P. (1977). Empirical item keying versus a rational approach to analyzing a psychological climate questionnaire. Applied Psychological Measurement, l(4), 489-500.

Jackson, D. (1970). A sequential system for personality scale development. In C.D. Spielberger (Ed.), Current topics in clinical and community psychology (pp. 61-96). New York, NY: Academic Press.

Janz, T.A., \& Pyke, S.W. (1997). [A survey of university students' perceptions of the chilly climate]. Unpublished raw data.

Jenkins, J., Gappa, J., \& Pearce, J. (1983). Removing bias: Guidelines for student-faculty communication. Annandale, VA: Speech communication Association.

Katz, P.A., Boggiano, A., \& Silvern, L. (1993). Theories of female personality. In F.L. Denmark \& M.A. Paludi, Psychology of women: A handbook of issues and theories (pp. 247-280). Westport, Connecticut: Greenwood Press.

King, J.E., \& Cooley, E.L. (1995). Achievement orientation and the impostor phenomenon among college students. Contemporary Educational Psychology, 20, 304-312.

Klonis, S., Endo, J., Crosby, F., Worell, J. (1997). Feminism as a life raft. Psychology of Women Quarterly, 21(3), 333-345.

Kohn, P.M., O'Brien, C., Pickering, D.I. (1996). Adaptiveness: A moderator of the adverse impact of hassles? Paper presented at the Fifth Annual In-House Convention of the Department of Psychology, York University, Toronto, ON.

Larkin, J. (1991). Sexual harassment: From the personal to the political. Atlantis, 17(1), 106-115.

Lay, C. (1996). Interpreting trait procrastination as lack of conscientiousness: Lower-order traits, higher-order factors, and the specificity issue. Paper presented at the Fifth Annual In-House Convention of the Department of Psychology, York University, Toronto, ON.

Levy, S. (1996). Fact book: York university. Toronto, ON: York University.

Long, S. (1977). Academic disaffection and the university student. Educational Studies, 3(1), 67-79.

Malovich, N.J., \& Stake, J.E. (1990). Sexual harassment on campus: Individual differences in attitudes and beliefs. Psychology of Women Quarterly, 15(1), 31-47.

McDaniel, S., \& Van Roosmalen, E. (1991). Sexual harassment in Canadian academe: Explorations of power and privilege. Atlantis, 17(1), 3-19. 
McKinney, K., Olson, C.V., \& Satterfield, A. (1988). Graduate students' experiences with and responses to sexual harassment. Journal of Interpersonal Violence, 3(3), 319-325.

Middleton, R. (1972). Alienation, race, and education. American Sociological Review, 28, 973-977.

Minnich, E.K. (1990). Transforming knowledge. Philadelphia, PA: Temple University Press.

Norusis, M.J. (1990). SPSS base system user's guide. Chicago, IL: SPSS Inc.

Pascarella, E.T., \& Terenzini, P.T. (1991). How college affects students. San Francisco, CA: Jossey-Bass Publishers.

Pedhazur, E.J., \& Schmelkin, L.P. (1991). Measurement, design, and analysis: An integrated approach. Hillsdale, NJ: Lawrence Erlbaum Associates Inc, Publishers.

Pyke, S.W. (1991). Women in universities: Still a chilly climate. Invited address, meeting of the Canadian Psychological Association, Calgary, AB, June.

Pyke, S.W. (1996). Sexual harassment and sexual intimacy in learning environments. Canadian Psychology, 37(1), 13-22.

Pyke, S.W. (1997). Education and the "woman question." Canadian Psychology, 38(3), 154-163.

Pyke, S.W., \& Maxwell, D.K. (1995, June). Doctoral student attrition: An analysis of the precipitating factors. Paper presented at the Annual Meeting of the Canadian Psychological Association, Charlottetown, PEI.

Reynolds, W.M. (1982). Development of reliable and valid short forms of the Marlowe-Crowne social desirability scale. Journal of Clinical Psychology, $38,119-125$.

Robinson, J.P., \& Shaver, P.R. (1973). Measures of social psychological attitudes. Ann Arbor, MI: Institute for Social Research, University of Michigan.

Sadker, M., \& Sadker, D. (1986, March). Sexism in the classroom: From grade school to graduate school. Phi Delta Kappa, pp. 512-525.

Sadker, M., \& Sadker, D. (1994). Failing at fairness: How our schools cheat girls. New York, NY: Simon \& Schuster.

Sandler, B.R., \& Hall, R.M. (1986). The campus climate revisited: Chilly for women faculty, administrators and graduate students. Washington, DC: Project on the Status and Education of Women, Association of American Colleges.

Schuckman, H. (1987). PhD recipients in psychology and biology: Do those with dissertation advisors of the same sex publish scholarly papers more frequently? American Psychologist, 42(11), 987-992. 
Seagram, B.C., Gould, J., \& Pyke, S.W. (1998). An investigation of gender and other variables on time to completion of doctoral degrees. Research in Higher Education, 39, 319-335.

Spender, D. (1982). Women of ideas and what men have done to them. Hammersmith, London: Pandora Press.

Strenta, A.C., Elliott, R., Adair, R., Matier, M., \& Scott, J. (1994). Choosing and leaving science in highly selective institutions. Research in Higher Education, 35(5), 513-547.

Templeman, J. (1994). Women and risk-taking: The overlooked dimension. In J. Gallivan, S.D. Crozier, \& V.M. Lalande (Eds.), Women girls and achievement. North York, ON: Captus Press.

Torrey, J.W. (1987). Phases of feminist re-vision in the psychology of personality. Teaching of Psychology, 14(3), 155-160.

Unger, R., \& Crawford, M. (1996). Women and gender: A feminist psychology. New York, NY: The McGraw-Hill Companies, Inc..

Williams, K.B., \& Cyr, R.R. (1992). Escalating commitment to a relationship: The sexual harassment trap. Sex Roles, 27, 47-72.

Westkott, M. (1979). Feminist criticism of the social sciences. Harvard Educational Review, 49(4), 422-430.

Wood, J.T. (1994). Gendered lives: Communication, gender and culture. Belmont, CA: Wadsworth Publishing Company. 